\title{
The Potential Effect of Ethyl Acetate fraction of Tephrosia Purpurea Linn Leaves (TPEAF) and Rutin in FCA induced Arthritis in experimental Animals
}

\author{
Sonali S Nipate ${ }^{\star}$, Chhaya S Chougule and Pramila S Yelmar \\ Department of Pharmacology, P.E.S's Modern College of Pharmacy, Yamunanagar, Nigdi, Pune, India
}

\section{Article Info}

*Corresponding author:
Sonali S Nipate
Associate Professor
Department of Pharmacology
P. E. S.'s Modern College of Pharmacy
Sector No. 21, Yamunanagar, Nigdi
Pune-411044
India
Tel: $91-9421061097$
E-mail: sonynipate@rediffmail.com

Received: February 2, 2019

Accepted: March 6, 2019

Published: March 12, 2019

Citation: Nipate SS, Chougule CS, Yelmar PS. The Potential Effect of Ethyl Acetate fraction of Tephrosia Purpurea Linn Leaves (TPEAF) and Rutin in FCA induced Arthritis in experimental Animals. Int J Tradit Med Appl. 2019; 1(1): 11-17.

doi: 10.18689/ijtma-1000103

Copyright: (c) 2019 The Author(s). This work is licensed under a Creative Commons Attribution 4.0 International License, which permits unrestricted use, distribution, and reproduction in any medium, provided the original work is properly cited.

Published by Madridge Publishers

\begin{abstract}
The aim of the present study is to investigate the anti arthritic activity of ethyl acetate fraction Tephrosia purpurea Linn leaves (TPEAF) at the dose of 200 and $400 \mathrm{mg} / \mathrm{kg}$ body weight and Rutin at the dose of $100 \mathrm{mg} / \mathrm{kg}$ body weight on FCA induced arthritis in experimental rats. Arthritis was induced by injecting a $0.1 \mathrm{ml}$ suspension of killed Mycobacterium tuberculosis bacteria $(0.1 \% \mathrm{w} / \mathrm{v})$ homogenized in liquid paraffin (Freund's complete adjuvant, FCA) into the right hind paw. Evaluation parameters such as Arthritic index, Paw edema was determined on respective days of experiment and pain perception parameters such as dorsal flexion pain, Stair climbing activity, and Motility score was recorded. The biochemical parameters like serum transaminases, hematological parameters, CRP (C-reactive protein), RF (Rheumatoid factor) level were determined.

From all the investigations it has been observed that TPEAF and Rutin showed significantly decreased in paw edema. The altered hematological parameters $(H b, R B C$, WBC, ESR, CRP, and RP) in the arthritic rats were significantly recovered to normal by administration of TPEAF and Rutin. Further, the radiological studies revealed TPEAF and Rutin showed anti-arthritic activity by indicating less abnormality in bone when compared to the disease control group. Findings from the present investigations showed that the TPEAF and Rutin exhibit significant anti-arthritic activity.
\end{abstract}

Keywords: Anti Arthritic; TPEAF; FCA; RF; CRP; Radiological analysis.

\section{Introduction}

Rheumatoid arthritis (RA) is a chronic autoimmune disease which affects the movement of joints, characterized by destruction of joint, loss of bone and cartilage tissue, synovial and systemic inflammation, increased level of auto antibodies most of which is a Rheumatoid factor (RF) [1-4]. RA at the start affects the synovial membrane of the joint which further leads to damage to both bone and cartilage tissue [5]. The release of pro-inflammatory mediators like cytokines, growth factors, RF involved in the pathogenesis of RA and again the release of PGE2 (prostaglandin E2) which is inflammatory mediators causes vasodilation, increases vascular permeability, pain, production of cytokine and protease in the affected joint area [6]. RA occurs in the peoples of aged 20 to 50 and incidences are 2-3 times higher in female than male [7]. RA is associated with major complications such as cardiovascular disorder (CVD), malignancy, pulmonary diseases $[8,9]$. A huge amount of oxygen free radicals are produced by macrophage at the site of injury which produces inflammatory responses and while neutralization by the antioxidant can reduce the inflammatory symptoms [10-12]. The key aspects in the treatment of RA are to the relief of pain, reduction of pannus formation, reduction of joint inflammation [13]. Nowadays Nonsteroidal anti-inflammatory 
drugs (NSAIDs), Disease-modifying antirheumatic drugs (DMARDs), glucocorticoids, immunosuppressant are used for the management of RA. These drugs have serious side effects which include gastrointestinal toxicity, kidney irritations, reproductive toxicity, and cardiovascular complications $[14,15]$.

In the present study, it was examined that Ethyl acetate Fraction of Tephrosia purpurea Linn leaves (TPEAF) and Rutin for anti-arthritic activity. Various parameters such as paw edema, hematological parameters, and pain perception parameters, radiological and histopathological study were evaluated for the assessment of anti-arthritic activity.

\section{Materials and Methods}

\section{Chemicals}

Freund's complete adjuvant was purchased from Sigma Aldrich pvt.Itd. U.S.A. Standard biochemical diagnostic kits were purchased from Transania Bio-medicals Limited. All the chemicals and reagents used were of analytical grade and procured from SRL (Mumbai, India), E. Merck (India).

\section{Plant material}

The leaves of Tephrosia purpurea Linn were collected from the month of June 2016. The plant was identified and authenticated by Department of Botany, Savitribai Phule Pune University, Pune and a Ref. No (A4/2016) was deposited in the herbarium for future references.

\section{Extraction of plant material and preparation of the fraction}

Dried, finely powdered leaves of Tephrosia purpurea Linn $(500 \mathrm{~g})$ were defatted with petroleum ether for 72 hours and were extracted with $95 \%$ ethanol for 48 hours. After filtration, the filtrate was concentrated and dried [16]. Ethyl acetate Fraction was prepared by adding $1 \mathrm{gm}$ of extract in $10 \mathrm{ml}$ distilled water and $10 \mathrm{ml}$ of ethyl acetate in separating funnel. Further on shaking two layers of which lower layer was isolated. This fraction was evaporated in a rotavapor at $40-50^{\circ} \mathrm{C}$ temperature under vacuum and stored in the refrigerator until further use for experimentation [17].

The dose of TPEAF was selected on the basis of toxicity study that have been studied earlier and from studies it was found that Tephrosia purpurea is not toxic in rat up to the dose of $2000 \mathrm{mg} / \mathrm{kg}$ [18].

\section{Experimental method}

The experiment was performed on healthy male albino Wistar rats $(180-220 \mathrm{gm})$ purchased from the National Institute of Bioscience, Pune, Maharashtra, India and acclimatized in the animal house of Modern College of Pharmacy, Nigdi, Pune, Maharashtra India-44 prior to the experimental study. The rats were grouped 6 for per cage under kept up the ordinary condition in an animal house (i.e.; 12 hours $/ 12$ hour light/dull calendar and $22 \pm 2^{\circ} \mathrm{C}$ with relative humidity $55 \pm 5 \%$ ) with free access to standard rat chow pellet and water all throughout the examination. The exploratory protocol was approved by the Institutional Animal Ethics Committee (IAEC) with protocol no. MCP/IAEC/04/2016.
Arthritis was induced by injecting a $0.1 \mathrm{ml}(0.1 \% \mathrm{w} / \mathrm{v})$ suspension of killed Mycobacterium tuberculosis bacteria homogenized in liquid paraffin (Freund's complete adjuvant) into the right hind paw [19]. Animals were divided into 6 groups of 6 rats each. Group I: The normal group was administered with normal saline. Group II: Disease control group, Group III: The standard group received Indomethacin (2 $\mathrm{mg} / \mathrm{kg}$ body weight) p.o. Group IV: The test group was administered with TPEAF at the doses $200 \mathrm{mg} / \mathrm{kg}$ body weight p.o. Group V: The test group was administered with TPEAF at the doses $400 \mathrm{mg} / \mathrm{kg}$ body weight p.o. Group Vl: The test group was administered with Rutin at the doses $100 \mathrm{mg} / \mathrm{kg}$ body weight $p . o$. The drug treatment was started from the $14^{\text {th }}$ day after chronic disease induction and continued till $28^{\text {th }}$ day.

\section{Evaluation of hematological, biochemical and other parameters}

On $7^{\text {th }}, 14^{\text {th }}, 21^{\text {st }}$ and $28^{\text {th }}$ day of experiment paw edema and the arthritic score was measured for the assessment of depth of inflammation. On the same days of the experiment pain perception parameters such as dorsal flexion pain test, stair climbing test, and motility test were performed. Body weight was measured on $7^{\text {th }}, 14^{\text {th }}, 21^{\text {st }}$ and $28^{\text {th }}$ day by using electronic balance and change in their body weight is recorded. On $28^{\text {th }}$ day blood withdrawn through retro-orbital vein puncture of all group by anesthetizing the animals with ketamine and biochemical parameters like hemoglobin content, Total WBC count, Total RBC count and ESR were analyzed. Whole blood was placed for the evaluation of ESR. The level of serum C-reactive protein (CRP) and the Rheumatoid factor was determined using the pathology laboratory method. Serum was then analyzed for lysosomal enzymes such as serum glutamate pyruvate transaminase (SGPT), serum glutamate oxaloacetate transaminase (SGOT) and alkaline phosphatase (ALP) by using SGPT, SGOT, and ALP standard analysis kits. Antioxidant enzymes level of SOD (Superoxide dismutase) and CAT (Catalase) were determined. Further animals were processed for histopathological and radiological assessment.

\section{Statistical data analysis}

Data obtained were subjected to one-way analysis of variance (ANOVA) Followed by Dunnett's test using Graph Pad Prism 5 software. The values are indicated in mean \pm SEM and ${ }^{*} P<0.05,{ }^{* *} P<0.01$ was considered significant.

\section{Results}

\section{Effect of TPEAF on paw edema}

Paw edema was measured by using vernier caliper on $7^{\text {th }}$, $14^{\text {th }}, 21^{\text {st }}$ and $28^{\text {th }}$ day of experiment and as shown in the figure 1 groups treated with TPEAF at the dose of 200 and 400 $\mathrm{mg} / \mathrm{kg}$ body weight and Rutin $100 \mathrm{mg} / \mathrm{kg}$ body weight showed significant reduction in paw edema after $21^{\text {st }}$ day of treatment when compared with the disease control group. 


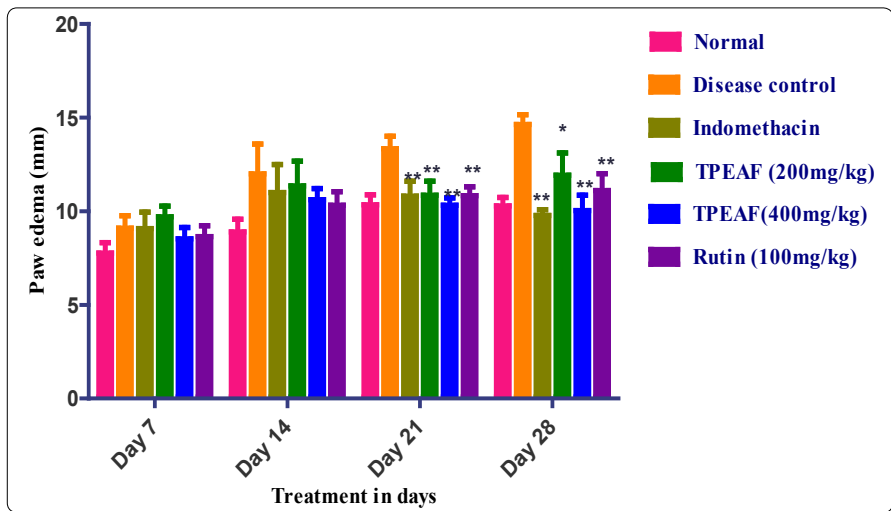

Figure 1. Effect of TPEAF (200 and $400 \mathrm{mg} / \mathrm{kg}$ ) and Rutin $(100 \mathrm{mg} / \mathrm{kg}$ ) on paw edema.

Values are expressed in mean \pm S.E.M. $(n=6) ;{ }^{*} p<0.05$, ${ }^{* *} p<0.01$ vs. Control group, Data analysed by One-way ANOVA test followed by Dunnett's multiple test for comparison.

\section{Effect of TPEAF on arthritic index}

As shown in table 1, there was a significant increase in rat arthritic index in disease control rats when compared to the normal group. Groups treated with TPEAF at the dose of 200 and $400 \mathrm{mg} / \mathrm{kg}$ body weight and Rutin $100 \mathrm{mg} / \mathrm{kg}$ body weight showed a significant reduction in the arthritic index when compared with the control group.

Table 1. Effect of TPEAF (200 and 400 mg/kg) and Rutin $(100 \mathrm{mg} / \mathrm{kg}$ ) on arthritic index.

\begin{tabular}{|c|c|c|c|c|}
\hline Exp.G & \multicolumn{4}{|c|}{ Arthritic Index } \\
\hline Day & $7^{\text {th }}$ & $14^{\text {th }}$ & $21^{\text {th }}$ & $28^{\text {th }}$ \\
\hline Normal & 0 & 0 & 0 & 0 \\
\hline Disease control & $1.6 \pm 0.24$ & $2.33 \pm 0.21$ & $2.5 \pm 0.22$ & $3 \pm 00$ \\
\hline Indomethacin & $1.6 \pm 0.24$ & $2.16 \pm 0.16$ & $0.66 \pm 0.21^{\text {** }}$ & $0.4 \pm 0.24^{* *}$ \\
\hline TPEAF $(200 \mathrm{mg} / \mathrm{kg})$ & $1.4 \pm 0.24$ & $1.83 \pm 0.30$ & $1 \pm 0.36^{* *}$ & $0.8 \pm 0.20^{* * *}$ \\
\hline TPEAF $(400 \mathrm{mg} / \mathrm{kg})$ & $1.4 \pm 0.24$ & $2 \pm 0.25$ & $0.50 \pm 0.22^{* *}$ & $0.4 \pm 0.24^{* *}$ \\
\hline Rutin $(100 \mathrm{mg} / \mathrm{kg})$ & $1.4 \pm 0.24$ & $2.16 \pm 0.30$ & $0.83 \pm 0.30^{\text {** }}$ & $0.60 \pm 0.24^{* * *}$ \\
\hline
\end{tabular}

\section{Effect of TPEAF on dorsal flexion pain test}

Dorsal flexion pain is pain perception parameter performed in specific day's interval of $7^{\text {th }}, 14^{\text {th }}, 21^{\text {st }}$ and $28^{\text {th }}$ day and table 2 showed that TPEAF at the dose of 200 and $400 \mathrm{mg} / \mathrm{kg}$ body weight and Rutin $100 \mathrm{mg} / \mathrm{kg}$ body weight showed the significant reduction in pain when compared with disease control group.

Table 2. Effect of TPEAF (200 and $400 \mathrm{mg} / \mathrm{kg}$ ) and Rutin (100 mg/kg) on dorsal flexion pain score.

\begin{tabular}{|c|c|c|c|c|}
\hline Exp.G & \multicolumn{4}{|c|}{ DORSAL FLEXION PAIN SCORE } \\
\hline Day & $7^{\text {th }}$ & $14^{\text {th }}$ & $21^{\text {th }}$ & $28^{\text {th }}$ \\
\hline Normal & 0 & 0 & 0 & 0 \\
\hline Disease control & $1.66 \pm 0.16$ & $1.83 \pm 0.16$ & $2 \pm 0.00$ & $2.0 \pm 0.00$ \\
\hline Indomethacin & $1.66 \pm 0.16$ & $1.66 \pm 0.21$ & $1.33 \pm 0.21^{\text {*t }}$ & $0.5 \pm 0.22^{* *}$ \\
\hline TPEAF $(200$ mg/kg) & $1.66 \pm 0.16$ & $1.66 \pm 0.21$ & $1.5 \pm 0.22^{* *}$ & $0.83 \pm 0.16^{* *}$ \\
\hline TPEAF (400 mg/kg) & $1.66 \pm 0.16$ & $1.66 \pm 0.21$ & $1.0 \pm 0.00^{* *}$ & $0.33 \pm 0.21^{* *}$ \\
\hline Rutin $(100 \mathrm{mg} / \mathrm{kg})$ & $1.66 \pm 0.16$ & $1.5 \pm 0.22$ & $1.66 \pm 0.16^{* *}$ & $0.83 \pm 0.16^{* *}$ \\
\hline
\end{tabular}

Values are expressed in mean \pm S.E.M. $(n=6) ;{ }^{*} p<0.05$, ${ }^{* \star} p<0.01$ vs. Control group, Data analysed by One-way ANOVA test followed by Dunnett's multiple test for comparison.

\section{Effect of TPEAF on stair climbing activity test}

Stair Climbing Activity test performed on $7^{\text {th }}, 14^{\text {th }}, 21^{\text {st }}$ and $28^{\text {th }}$ day and as shown in the table 3 , groups treated with TPEAF at the dose of 200 and $400 \mathrm{mg} / \mathrm{kg}$ body weight and Rutin 100 $\mathrm{mg} / \mathrm{kg}$ body weight showed significant increased in stair climbing score when compared with the disease control group.

Table 3. Effect of TPEAF (200 and $400 \mathrm{mg} / \mathrm{kg}$ ) and Rutin (100 mg/kg) on stair climbing score.

\begin{tabular}{|l|c|c|c|c|}
\hline Exp.G & \multicolumn{4}{|c|}{ STAIR CLIMBING SCORE } \\
\hline Day & $7^{\text {th }}$ & $\mathbf{1 4}^{\text {th }}$ & $\mathbf{2 1}^{\text {th }}$ & $\mathbf{2 8}^{\text {th }}$ \\
\hline Normal & 3 & 3 & $2.66 \pm 0.21$ & $2.5 \pm 0.22$ \\
\hline Disease control & $1.16 \pm 0.16$ & $1.00 \pm 0.00$ & $0.5 \pm 0.22$ & $0.16 \pm 0.16$ \\
\hline Indomethacin & $1.33 \pm 0.21$ & $1.00 \pm 0.00$ & $1.00 \pm 0.00^{* *}$ & $2.33 \pm 0.33^{* *}$ \\
\hline TPEAF $(\mathbf{2 0 0} \mathrm{mg} / \mathrm{kg})$ & $0.83 \pm 0.16$ & $0.83 \pm 0.16$ & $1.66 \pm 0.16^{* *}$ & $1.33 \pm 0.21^{* *}$ \\
\hline TPEAF $(\mathbf{4 0 0} \mathbf{~ m g} / \mathbf{k g})$ & $0.83 \pm 0.16$ & $0.83 \pm 0.16$ & $1.33 \pm 0.21^{* *}$ & $2.33 \pm 0.21^{* *}$ \\
\hline Rutin $(\mathbf{1 0 0} \mathrm{mg} / \mathbf{k g})$ & $0.83 \pm 0.16$ & $0.83 \pm 0.16$ & $0.83 \pm 0.16^{* *}$ & $1.16 \pm 0.16^{* *}$ \\
\hline
\end{tabular}

Values are expressed in mean \pm S.E.M. $(n=6)$; ${ }^{*} p<0.05$, ${ }^{* *} p<0.01$ vs. Control group, Data analysed by One-way ANOVA test followed by Dunnett's multiple test for comparison.

\section{Effect of TPEAF on motility test}

Motility test is one of the pain perception parameters which was performed at the interval of $7^{\text {th }}, 14^{\text {th }}, 21^{\text {st }}$ and $28^{\text {th }}$ day and as shown in table 4, it was observed that treatment TPEAF at the dose of 200 and $400 \mathrm{mg} / \mathrm{kg}$ body weight and Rutin $100 \mathrm{mg} / \mathrm{kg}$ body weight showed significantly increased in motility when compared to the disease control group.

Table 4. Effect of TPEAF (200 and $400 \mathrm{mg} / \mathrm{kg}$ ) and Rutin (100 mg/kg) on motility score.

\begin{tabular}{|l|c|c|c|c|}
\hline Exp.G & \multicolumn{4}{|c|}{ MOTILITY SCORE } \\
\hline Day & $7^{\text {th }}$ & $\mathbf{1 4 ^ { \text { th } }}$ & $\mathbf{2 1}^{\text {th }}$ & $\mathbf{2 8}^{\text {th }}$ \\
\hline Normal & 0 & 0 & 0 & 0 \\
\hline Disease control & $1.44 \pm 0.16$ & $1.90 \pm 0.16$ & $2 \pm 0.00$ & $2.0 \pm 0.00$ \\
\hline Indomethacin & $1.23 \pm 0.26$ & $1.60 \pm 0.21$ & $1.33 \pm 0.21$ & $0.5 \pm 0.22^{\text {** }}$ \\
\hline TPEAF $(\mathbf{2 0 0} \mathbf{~ m g} / \mathbf{k g})$ & $1.60 \pm 0.21$ & $1.90 \pm 0.21$ & $1.5 \pm 0.22^{*}$ & $0.82 \pm 0.16^{* *}$ \\
\hline TPEAF $(\mathbf{4 0 0} \mathbf{~ m g} / \mathbf{k g})$ & $1.62 \pm 0.16$ & $1.66 \pm 0.21$ & $1.0 \pm 0.00^{* *}$ & $0.22 \pm 0.21^{* *}$ \\
\hline Rutin $(\mathbf{1 0 0} \mathbf{~ m g} / \mathbf{k g})$ & $1.36 \pm 0.21$ & $1.45 \pm 0.22$ & $1.66 \pm 0.16^{*}$ & $0.73 \pm 0.16^{* *}$ \\
\hline
\end{tabular}

Values are expressed in mean \pm S.E.M. $(n=6) ;{ }^{*} p<0.05$, ${ }^{* *} p<0.01$ vs. Control group, Data analysed by One-way ANOVA test followed by Dunnett's multiple test for comparison.

\section{Effect of TPEAF on body weight}

As shown in the table 5, disease control group showed remarkably decreased in the body weight as compared to the normal group. Under similar conditions, Indomethacin, TPEAF (200 and $400 \mathrm{mg} / \mathrm{kg}$ body weight) and Rutin (100 mg/kg body weight) treated groups showed a significant gain in body weight.

Table 5. Effect of TPEAF (200 and $400 \mathrm{mg} / \mathrm{kg}$ ) and Rutin (100 mg/kg) on body weight.

\begin{tabular}{|l|c|c|c|c|}
\hline Exp.G & \multicolumn{4}{|c|}{ BODY WEIGHT (gm) } \\
\hline Day & $7^{\text {th }}$ & $\mathbf{1 4}^{\text {th }}$ & $\mathbf{2 1}^{\text {th }}$ & $\mathbf{2 8}^{\text {th }}$ \\
\hline Normal & $167.7 \pm 3.36$ & $195.83 \pm 5.11$ & $217 \pm 4.5$ & $230.28 \pm 9.30$ \\
\hline Disease control & $156.2 \pm 3.73$ & $155.8 \pm 5.45$ & $144.5 \pm 7.3$ & $123.2 \pm 23.12$ \\
\hline Indomethacin & $160.8 \pm 5.58$ & $150.9 \pm 5.21$ & $173 \pm 12.59^{*}$ & $193.07 \pm 2.82^{*}$ \\
\hline TPEAF $(\mathbf{2 0 0} \mathbf{m g} / \mathbf{k g})$ & $166.4 \pm 6.28$ & $160 \pm 3.21$ & $169.12 \pm 4.33^{*}$ & $173.01 \pm 6.09^{*}$ \\
\hline TPEAF(400 $\mathbf{~ g / k g ) ~}$ & $163.43 \pm 3.07$ & $156 \pm 2.21$ & $178.3 \pm 5.12^{*}$ & $192.32 \pm 2.76^{*}$ \\
\hline Rutin $(\mathbf{1 0 0} \mathbf{~ m g} / \mathbf{k g})$ & $160.4 \pm 6.7$ & $155 \pm 6.22$ & $166.3 \pm 4.16^{*}$ & $170.30 \pm 6.20^{*}$ \\
\hline
\end{tabular}

Values are expressed in mean \pm S.E.M. $(n=6) ;{ }^{*} p<0.05$, ${ }^{* *} p<0.01$ vs. Control group, Data analysed by One-way ANOVA test followed by Dunnett's multiple test for comparison. 


\section{Effect of TPEAF on hematological parameters}

In FCA induced untreated group, there was an incredible decreased in RBC count and hemoglobin and also a marked increased in WBC count and ESR. However, treatment with TPEAF reversed these altered hematological parameters and the effects for TPEAF were found to be dose dependent. As shown in figure 2, it was observed that after the treatment of TPEAF (200 and 400 mg/kg body weight) and Rutin (100 mg/ $\mathrm{kg}$ body weight), results showed significantly increased in the level of RBC and hemoglobin as well as significantly decreased the level of raised WBC and ESR in treatment groups.

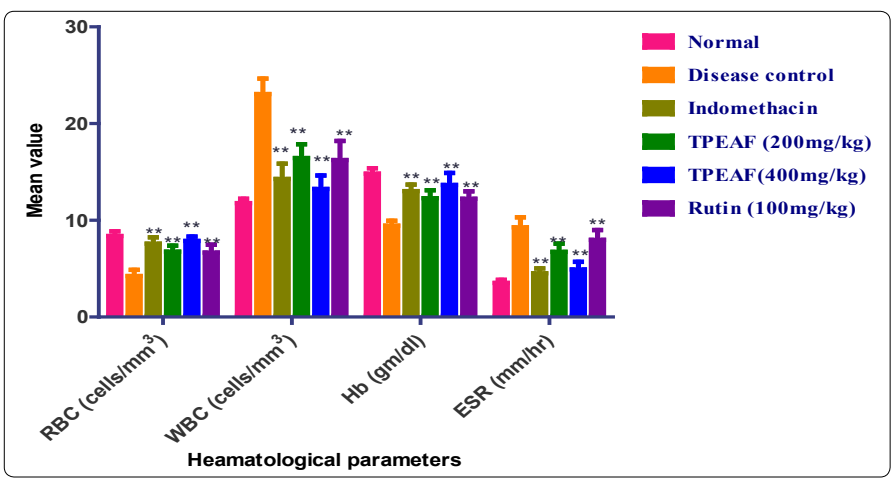

Figure 2. Effect of TPEAF (200 and $400 \mathrm{mg} / \mathrm{kg}$ ) and Rutin (100 mg/kg) Hematological parameters.

Values are expressed in mean \pm S.E.M. $(n=6) ;{ }^{*} p<0.05$, ${ }^{* *} p<0.01$ vs. Control group, Data analysed by One-way ANOVA test followed by Dunnett's multiple test for comparison.

\section{Effect of TPEAF on serum transaminases}

In figure 3, there was a significant increased in the lysosomal enzyme in disease control rats when compared to normal groups. Groups treated with TPEAF (200 and $400 \mathrm{mg} /$ $\mathrm{kg}$ body weight) and Rutin (100 mg/kg body weight) showed a significant reduction in rat lysosomal enzyme when compared with the control group.

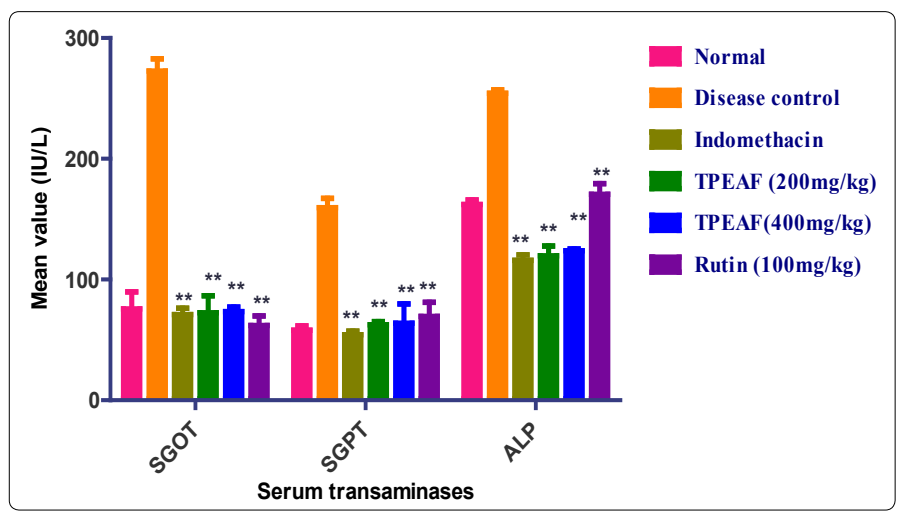

Figure 3. Effect of TPEAF (200 and $400 \mathrm{mg} / \mathrm{kg}$ ) and Rutin (100 mg/kg) on serum transaminases.

Values are expressed in mean \pm S.E.M. $(n=6) ;{ }^{*} p<0.05$, ${ }^{* *} p<0.01$ vs. Control group, Data analysed by One-way ANOVA test followed by Dunnett's multiple test for comparison.

\section{Effect of TPEAF on biochemical parameters}

The grade of RF factor and CRP showed significantly increased in the RF and CRP levels in the disease control group, which were observed to be significantly reduced in TPEAF and Rutin treated groups (Figure 4).

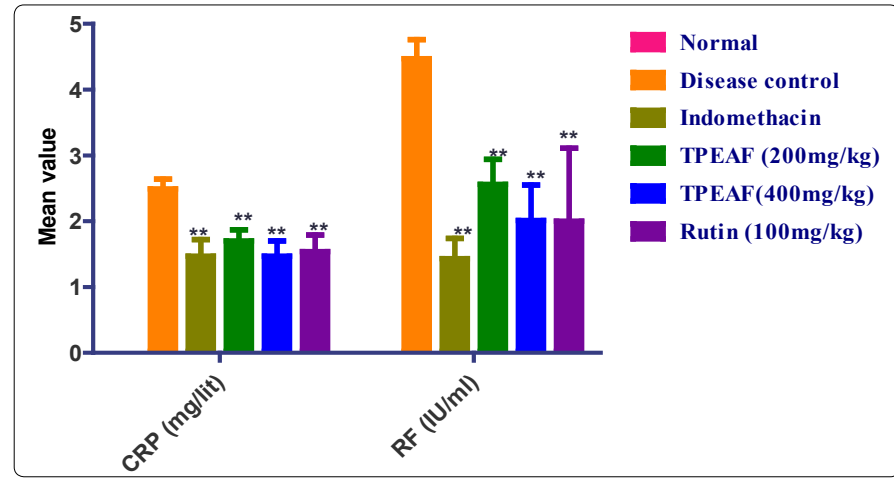

Figure 4. Effect of TPEAF (200 and $400 \mathrm{mg} / \mathrm{kg}$ ) and Rutin (100 mg/kg) on CRP and RF level.

Values are expressed in mean \pm S.E.M. $(n=6) ;{ }^{*} p<0.05$, ${ }^{* *} p<0.01$ vs. Control group, Data analysed by One-way ANOVA test followed by Dunnett's multiple test for comparison.

\section{Effect of TPEAF on antioxidant enzymes level}

Antioxidant enzymes such as SOD and CAT levels were assessed on $28^{\text {th }}$ day. As shown in figure 5 it was found that in the disease control group there was decreased level of SOD and CAT when compared to the normal group which was observed to be significantly normalized in TPEAF and Rutin treated groups.

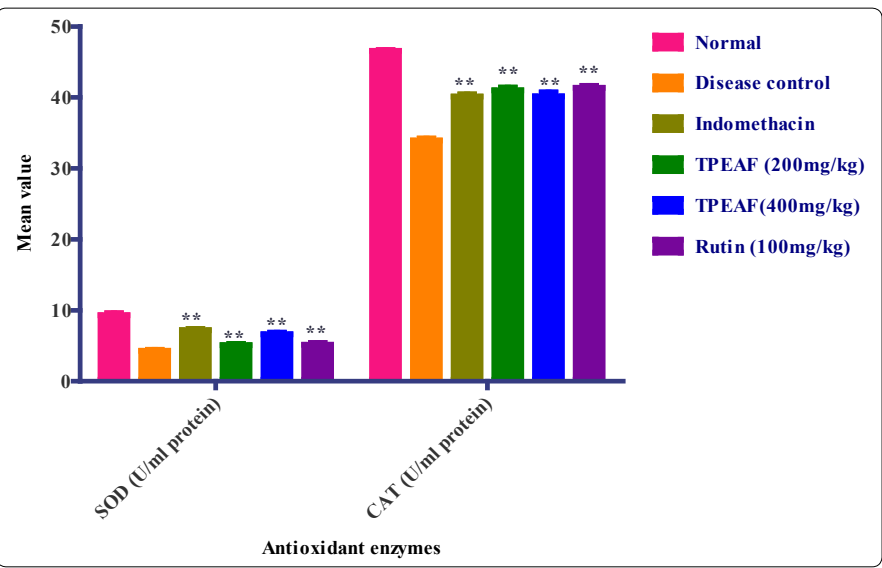

Figure 5. Effect of TPEAF (200 and $400 \mathrm{mg} / \mathrm{kg}$ ) and Rutin $(100 \mathrm{mg} / \mathrm{kg})$ antioxidant enzymes level.

Values are expressed in mean \pm S.E.M. $(n=6) ;{ }^{*} p<0.05$, ${ }^{* *} p<0.01$ vs. Control group, Data analysed by One-way ANOVA test followed by Dunnett's multiple test for comparison.

\section{Histopathological evaluation}

As shown in figure 6 histopathological studies of left hind paw in Group I - showed the histopathology of the normal ankle joint. Group II - arthritic rat joint showed prominent abnormalities from the normal joint like edema formation, degeneration with partial erosion of the cartilage, destruction of bone and extensive infiltration of inflammatory exudates in the articular surface. Group III - Indomethacin treated rat joint showed normal bone with less cellular infiltrates. Group IV showed cellular infiltrates on the articular surface with less cartilage destruction. Group V - showed less inflammatory signs like scanty cellular infiltrates, the absence of edema formation and normal bone structure. Group VI - showed mild pannus formation in which the proliferation of fibrous tissue noticed from the cartilage. 

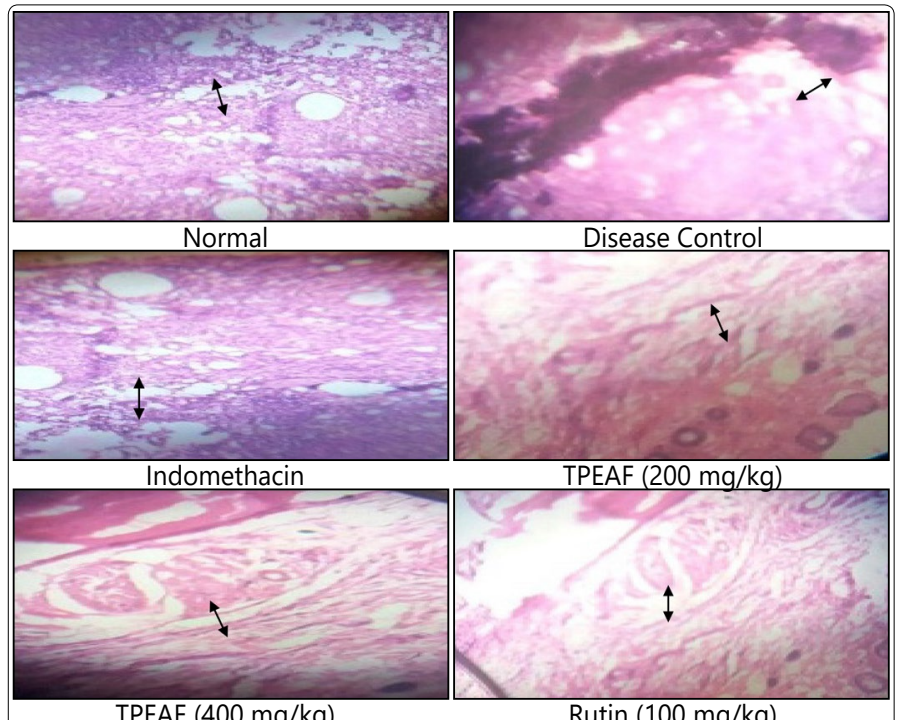

TPEAF $(400 \mathrm{mg} / \mathrm{kg})$

Rutin $(100 \mathrm{mg} / \mathrm{kg})$

Figure 6. Effect of TPEAF (200 and $400 \mathrm{mg} / \mathrm{kg}$ ) and Rutin $(100 \mathrm{mg} / \mathrm{kg}$ ) on histopathology of left hind paw.

\section{Radiological analysis}

The results were observed from X-ray (figure 7) was the normal group animals showed an absence of soft tissue swelling and bony destruction. The arthritis control group animals were found with soft tissue swelling along with the narrowing of joint spaces and sign of bony destruction. The TPEAF and Rutin groups have shown prevention against bony destruction and narrowing of joint spaces by showing less soft tissue. The Indomethacin treatment has not shown tissue swelling and bone destruction.

\section{Discussion}

Arthritis is the inflammatory autoimmune disorder which is associated with swelling, damage to bone and cartilage of synovial joint results in severe pain and disability [20]. Nowadays plethoras of medicinal herbal plants are studied and are compared with the conventional medicines to treat RA by alleviating the symptoms [21]. RA is an inflammatory disease and plant Tephrosia purpurea Linn possesses an antiinflammatory activity [22]. The present study was carried out with the aim that to treat the symptoms of RA. FCA is commonly used and widely accepted animal model to evaluate anti arthritic activity and this model contributes to the similar pathological symptoms of RA patient to the adjuvant-induced arthritic rats [23].

In FCA induced model inflammatory events occurs by means of release of TNF- $\alpha$ and IL- 6 other inflammatory mediators (histamine, serotonin), prostaglandins which result in the increase in thickness and swelling of paw $[24,25]$. All the groups showed an increase in the paw edema and inflammation except normal group. In the present study, results showed that treatment of TPEAF, Rutin and Indomethacin significantly decreased paw edema by inhibiting inflammatory events.

TPEAF and Rutin treatment groups showed a significant reduction in the arthritic score as compared to the disease control group on day $21^{\text {st }}$ of treatment and it showed no significant variation in the results when compared to the normal group on $28^{\text {th }}$ day of treatment. This effect might be due to the reduction in the release of prostaglandins (PG) and invasion of granulocytes (Neutrophils) [26,27].

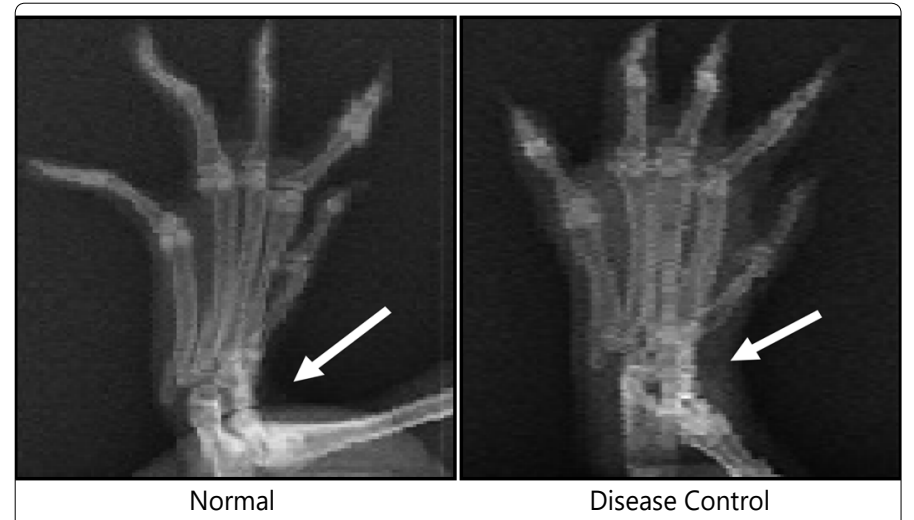

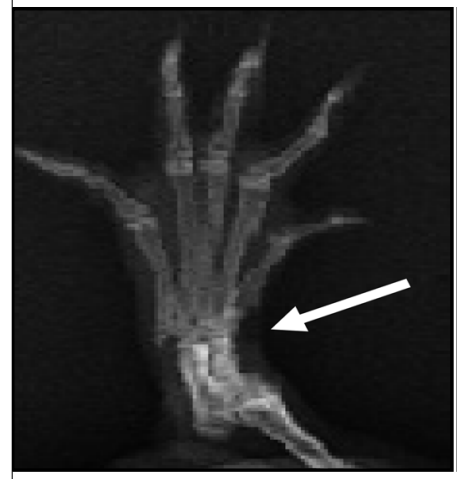

Indomethacin)

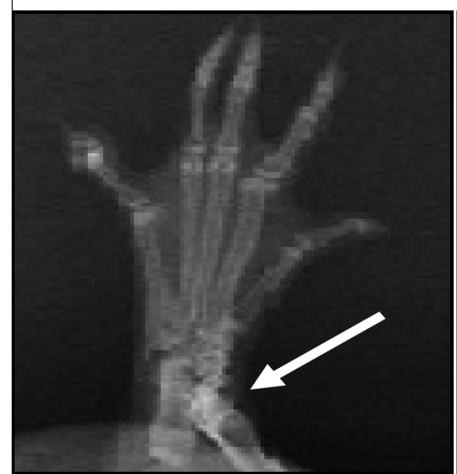

TPEAF $(400 \mathrm{mg} / \mathrm{kg})$

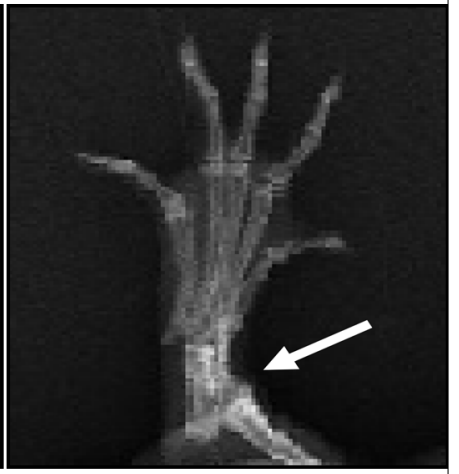

TPEAF $(200 \mathrm{mg} / \mathrm{kg})$

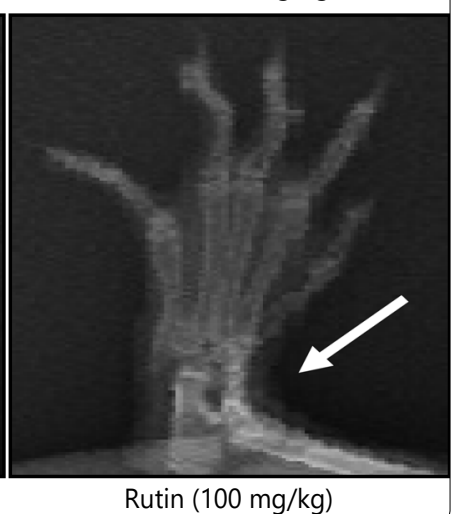

Figure 7. Effect of TPEAF (200 and $400 \mathrm{mg} / \mathrm{kg}$ ) and Rutin $(100 \mathrm{mg} / \mathrm{kg}$ ) on radiology of left hind paw.

RA is associated with the constant and chronic inflammation and pain of the joints which leads to the disability of walking [28]. In the present study to detail this fact various pain perception parameters such as dorsal flexion pain test, stair climbing test, and motility test were performed. The results of these tests showed that significant improvement in the walking ability and stair climbing activity in TPEAF and Rutin treatment groups as compared to the disease control groups.

RA is related to the inflammatory condition which causes the reduction in absorption of food nutrients from intestine [29]. In the present investigation, results showed that the disease control group failed to gain weight, while other treatment groups showed a significant improvement in body weight by absorption of nutrients. 
Anemia is one of the symptomatic conditions of RA, where the level of $\mathrm{RBC}$ and $\mathrm{Hb}$ decreases due to some disturbances occurs in the erythropoietin levels and premature destruction of RBC [30]. In the present investigation, TPEAF and Rutin group showed significant restoration of $\mathrm{RBC}$ and $\mathrm{Hb}$ level in comparison with disease control group.

Increased number of WBC represents the stimulation of the defense system of the body as they invade foreign particles comes in contact with them [31]. In the present investigation treatment of TPEAF and Rutin showed the restoration of WBC to its normal count which represents the immunomodulatory effect of TPEAF and Rutin.

Disease control groups showed the increased level of Erythrocyte sedimentation rate (ESR) which indicates the inflammatory conditions. Other treatment groups showed a significantly reduction in ESR. On the other hand increased level of RF shows the initialization of inflammatory processes by the release of inflammatory proteins in the system and this disturbing level of RF normalized on the treatment of TPEAF and Rutin [32]. Increased CRP level is also an indicator of RA [33]. On the treatment of TPEAF and Rutin, CRP level gets to the normal value as compared to disease control group.

The elevated transaminase enzymes level represents the hepatic and kidney impairment, where the SGOT and SGPT released from the damaged hepatic cells and also having the role in the development of inflammatory mediators $[34,35]$. In present study, it was found that treatment of TPEAF and Rutin showed the normalized level of SGOT and SGPT by restoring them to the normal level as compared to disease control group. This result showed the hepatoprotective and renal protective effect of TPEAF and Rutin. The increased level of ALP causes bone erosion and further leads to the destruction of bone and organ $[36,37]$. It was found that treatment of TPEAF and Rutin significantly reduced to restore the ALP level in comparison with the disease control group.

Formation of reactive oxygen radicals forms autoantibody against autoantigens that leads to autoimmune diseases like rheumatoid arthritis [38]. An antioxidant enzyme like SOD and CAT reacts with these free radicals which are an indicator of activation of the antioxidant defense system [39]. In the present study results showed that the treatment of TPEAF and Rutin increased the level of SOD and CAT as compared to the disease control group.

In the present study, histological and radiological results showed that TPEAF and Rutin treatment groups showed less destruction of bone and cartilage tissue, reduced paw swelling and reduced hyperplasia. This result revealed that TPEAF and Rutin are effective in bone destruction.

From the above results, it can be say that TPEAF and Rutin are having a great effect in alleviating the inflammatory symptoms by reducing paw edema and arthritic score. The findings also showed that TPEAF and Rutin activated the immune system as they increased the number of WBC and antioxidant enzymes. Other supporting results showed that treatment of TPEAF and Rutin restored hematological parameters to the normal, showed hepatoprotective and renal protective activity. These results showed that TPEAF and Rutin have effective treatment in arthritic activity.

\section{Conclusion}

Treatment of TPEAF and Rutin showed effective antiinflammatory by reducing release of inflammatory mediator effect as well as reduced the destruction of joint structure. Treatment also showed reduction of paw edema, normalized weight gain and radical scavenging activity and improved health status. From these results it can be conclude that TPEAF and Rutin can be used as medicinal alternative in arthritis.

\section{Conflict of Interest}

There is no conflict of interest.

\section{References}

1. Islander $U$, Jochems $C$, Lagerquist MK, Forsblad-d'Elia $H$, Carlsten $H$. Estrogens in rheumatoid arthritis; the immune system and bone. Mol Cell Endocrinol. 2011; 335(1): 14-29. doi: 10.1016/j.mce.2010.05.018

2. Scott DL, Wolfe F, Huizinga TW. Rheumatoid arthritis. Lancet. 2010; 376(9746): 1094-1108. doi: 10.1016/S0140-6736(10)60826-4

3. Kahlenberg JM, Fox DA. Advances in the medical treatment of rheumatoid arthritis. Hand Clin. 2011; 27(1): 11-20. doi: 10.1016/j.hcl.2010.09.002

4. Wijbrandts CA, Tak PP. Prediction of response to targeted treatment in rheumatoid arthritis. Mayo Clin Proc. 2017; 92(7): 1129-1143. doi: 10.1016/j.mayocp.2017.05.009

5. Kyei S, Koffuor GA, Boampong JN. Antiarthritic effect of aqueous and ethanolic leaf extracts of Pistia stratiotes in adjuvant-induced arthritis in Sprague-Dawley rats. J Exp Pharmacol. 2012; 4: 41-51. doi: 10.2147/JEP. S29792

6. De Mattei M, Varani K, Masieri FF, et al. Adenosine analogs and electromagnetic fields inhibit prostaglandin E2 release in bovine synovial fibroblasts. Osteoarthritis Cartilage. 2009; 17(2): 252-262. doi: 10.1016/j. joca.2008.06.002

7. Hooghof JT, Mellema JJ, Posthumus MD, van Raaij JJ. A Woman with Rheumatoid Arthritis and a Bilateral Fracture of the Proximal Tibia. Case Rep Orthop. 2016; 2016: 5094906. doi: 10.1155/2016/5094906

8. Cronstein BN. Interleukin-6. Bull NYU Hosp Jt Dis. 2007; 65(1): S11-S15.

9. Cojocaru M, Cojocaru IM, Silosi I, Vrabie CD, Tanasescu R. Extra-articular manifestations in rheumatoid arthritis. Maedica (Buchar). 2010; 5(4): 286-291.

10. Delaporte RH, Sánchez GM, Cuellar AC, Giuliani A, de Mello JC. Antiinflammatory activity and lipid peroxidation inhibition of iridoid lamiide isolated from Bouchea fluminensis (Vell.) Mold.(Verbenaceae). J Ethnopharmacol. 2002; 82(2-3): 127-130.

11. Hadjigogos $K$. The role of free radicals in the pathogenesis of rheumatoid arthritis. Panminerva Med. 2003; 45(1): 7-13.

12. Lund-Olesen K. Oxygen tension in synovial fluids. Arthritis Rheum. 1970; 13(6): 769-776.

13. Li NG, Shi ZH, Tang YP, Duan JA. Discovery of selective small molecular TACE inhibitors for the treatment of rheumatoid arthritis. Curr Med Chem. 2012; 19(18): 2924-2956.

14. Rainsford KD. Anti-inflammatory drugs in the 21st century. Subcell Biochem. 2007; 42: 3-27.

15. Wang $M$, Li K, Nie $Y$, Wei $Y$, Li X. Antirheumatoid arthritis activities and chemical compositions of phenolic compounds-rich fraction from Urtica atrichocaulis, an endemic plant to China. Evid Based Complementary Altern Med. 2012; 2012. doi: 10.1155/2012/818230 
16. Jain A, Singhai AK, Dixit VK. A comparative study of ethanol extract of leaves of Tephrosia purpurea pers and the flavonoid isolated for hepatoprotective activity. Indian J Pharm Sci. 2006; 68 (6): 740-743. doi: $10.4103 / 0250-474 X .31006$

17. Soni K, Kumar PS, Saraf MN. Antioxidant activity of fraction of Tephrosia purpurea linn. Indian J Pharm Sci. 2006; 68(4): 456-460. doi: 10.4103/0250474X.27817

18. Hussain T, Fareed S, Siddiqui HH, Vijaykumar M, Rao CV. Acute and subacute oral toxicity evaluation of Tephrosia purpurea extract in rodents. Asian Pac J Trop Dis. 2012; 2(2): 129-132. doi: 10.1016/S22221808(12)60030-9

19. Bihani GV, Rojatkar SR, Bodhankar SL. Anti-arthritic activity of methanol extract of Cyathocline purpurea (whole plant) in Freund's complete adjuvant-induced arthritis in rats. Biomed \& Aging Pathology. 2014; 4(3): 197-206. doi: 10.1016/j.biomag.2014.04.007

20. Mclnnes IB, Schett $G$. The pathogenesis of rheumatoid arthritis. N Engl J Med. 2011; 365(23): 2205-2219. doi: 10.1056/NEJMra1004965

21. Verpoorte R. Exploration of nature's chemodiversity: the role of secondary metabolites as leads in drug development. Drug Discovery Today. 1998; 3(5): 232-238. doi: 10.1016/S1359-6446(97)01167-7

22. Gopalakrishnan S, Vadivel E, Dhanalakshmi K. Anti-inflammatory and analgesic activities of Tephrosia purpurea Linn. aerial and root extracts. J Pharm Res. 2010; 3(5): 1103-1106.

23. Shabbir A, Shahzad M, Ali A, Zia-ur-Rehman M. Anti-arthritic activity of N'-((2, 4-dihydroxyphenyl) methylidene)-2-(3, 4-dimethyl-5, 5-dioxidopyrazolo (4, 3-c) (1, 2) benzothiazin-1 (4H)-yl) acetohydrazide. Eur J Pharmacol. 2014; 738: 263-272. doi: 10.1016/j.ejphar.2014.05.045

24. Wahane VD, Kumar VL. Atorvastatin ameliorates inflammatory hyperalgesia in rat model of monoarticular arthritis. Pharmacol Res. 2009; 61(4): 329-333. doi: 10.1016/j.phrs.2009.11.006

25. Johnston B, Burns AR, Kubes P. A role for mast cells in the development of adjuvant-induced vasculitis and arthritis. Am J Pathol. 1998; 152(2): 555-563.

26. Babu NP, Pandikumar $P$, Ignacimuthu $S$. Lysosomal membrane stabilization and anti-inflammatory activity of Clerodendrum phlomidis Lf, a traditional medicinal plant. J Ethnopharmacol. 2011; 135(3): 779-785. doi: 10.1016/j. jep.2011.04.028

27. Alamgeer HU, Uttra AM, Rasool S. Evaluation of in vitro and in vivo antiarthritic potential of Berberis calliobotrys. BMC Complement Altern Med. 2017; 17: 371. doi: 10.1186/s12906-017-1879-9
28. Zhang W, Dai SM. Mechanisms involved in the therapeutic effects of Paeonia lactiflora Pallas in rheumatoid arthritis. Int Immunopharmacol. 2012; 14(1): 27-31. doi: 10.1016/j.intimp.2012.06.001

29. Patil KS, Suryavanshi J. Effect of Celastrus paniculatus Willd. seed on adjuvant induced arthritis in rats. Pharmacogn Mag. 2007; 3(11): 177-181.

30. Whale M. Anemia in patients with rheumatoid arthritis. Z Rheumatol. 2012; 71(10): 864-868. doi: 10.1007/s00393-011-0925-0

31. Ekambaram S, Perumal SS, Subramanian V. Evaluation of antiarthritic activity of Strychnos potatorum Linn seeds in Freund's adjuvant induced arthritic rat model. BMC Complement Altern Med. 2010; 10: 56. doi: 10.1186/1472-6882-10-56

32. Kim W, Park S, Choi C, et al. Evaluation of anti-inflammatory potential of the new ganghwaljetongyeum on adjuvant-induced inflammatory arthritis in rats. Evid Based Complement Alternat Med. 2016; 2016: 1230294. doi: $10.1155 / 2016 / 1230294$

33. Pepys MB, Hirschfield GM. C-reactive protein: a critical update. J Clin Invest. 2003; 111(12): 1805-1812. doi: 10.1172/JCI18921

34. Ozer J, Ratner M, Shaw M, Bailey W, Schomaker S. The current state of serum biomarkers of hepatotoxicity. Toxicology. 2008; 245(3): 194-205. doi: 10.1016/j.tox.2007.11.021

35. Kadam P, Subhash LB. Antiarthritic activity of ethanolic seed extracts of Diplocyclos palmatus (L) C. Jeffrey in experimental animals. Der Pharm Lett. 2013; 5: 233-242.

36. Rehman Q, Lane NE. Bone loss: Therapeutic approaches for preventing bone loss in inflammatory arthritis. Arthritis Res. 2001; 3(4): 221-227. doi: 10.1186/ar305

37. Niino-Nanke $Y$, Akama H, Hara M, Kashiwazaki S. Alkaline phasphatase (ALP) activity in rheumatoid arthritis: its clinical significance and synthesis of ALP in RA synovium. Ryumachi. 1998; 38(4): 581-588.

38. Namazi MR. Neurogenic dysregulation, oxidative stress, autoimmunity, and melanocytorrhagy in vitiligo: can they be interconnected? Pigment Cell Res. 2007; 20(5): 360-363. doi: 10.1111/j.1600-0749.2007.00408.x

39. Zuo J, Xia Y, Li X, Chen JW. Therapeutic effects of dichloromethane fraction of Securidaca inappendiculata on adjuvant-induced arthritis in rat.J Ethnopharmacol.2014; 153(2):352-358. doi: 10.1016/j.jep.2014.02.015 